\title{
humanidades
}

Revista humanidades

Enero-junio, 2016 •Volumen 6, número 1 • ISSN 2215-3934・pp. 1-39

\section{Identidad, cohesión y patrimonio: Evolución de las políticas culturales en México}

DOI: http://dx.doi.org/10.15517/h.v6i1.24959

\section{Ángeles Ortiz Espinoza}

Maestra en Administración y Políticas Públicas. Profesora en la Universidad del Centro de México (UCEM). Correo electrónico: allure.spinoza@gmail.com

\section{Mario Gutiérrez, Díaz}

Licenciado en Historia. Investigador en el Centro de Investigación y Docencia Económicas (CIDE), Aguascalientes, México. Correo electrónico:

mario.gtzd@gmail.com

\section{Luis Alberto Hernández, Alba}

Licenciado en Historia. Investigador en el Centro de Investigación y Docencia Económicas (CIDE), Aguascalientes, México. Correo electrónico:

historiador.alberto.hdez.alba@gmail.com

Todos los derechos reservados. Universidad de Costa Rica. Esta revista se encuentra licenciada con Creative Commons Reconocimiento-NoComercial-SinObraDerivada 3.0 Costa Rica.

Correo electrónico: humanidades@ucr.ac.cr / Sitio web: http://revistas.ucr.ac.cr/index.php/humanidades 


\title{
Identidad, cohesión y patrimonio: Evolución de las políticas culturales en México
}

\section{Resumen}

El presente texto tiene como objetivo hacer una revisión histórica de las estrategias y mecanismos implementados en las políticas culturales en México. El interés de presentar esta breve reseña radica en el deseo de presentar a investigadores, estudiantes y hacedores de política, un punto de partida para el análisis y desarrollo de adecuadas políticas públicas relacionadas con el tema. El documento está dividido en cinco partes, la primera es una breve introducción en la que se exponen los objetivos y los planteamientos del trabajo. En la segunda parte se explica el desarrollo de las políticas culturales en los periodos históricos del México posindependiente y en el porfiriato. En la tercera y en la cuarta parte se hace un análisis de las políticas culturales en la época contemporánea. Por último, se plantean ciertas reflexiones y observaciones con respecto al desarrollo de las políticas culturales en México.
Palabras clave: Política cultural, identidad, cohesión, patrimonio.

\section{Identity, Cohesion and Heritage: Evolution of Cultural Policy in Mexico}

\begin{abstract}
This paper aims to make a historical review of the strategies and mechanisms implemented cultural policies in Mexico. The interest to present this brief lies in the desire to present to researchers, students and policy makers a starting point for the analysis and development of appropriate public policies related to the topic. The document is divided into five parts: the first is a brief introduction that outlines the objectives and approaches of work. In the second part, they are explained the cultural policies of two periods in Mexican history: the post-independence stage and the porfiriato. While in the third and fourth part, an analysis of cultural policies in the modern era it is done. Finally, this study raises some reflections and comments on the development of cultural policies in Mexico. For reasons of space, the text does not dwell on the description of the mechanisms that implement cultural policies.
\end{abstract}

\author{
Keywords: Cultural \\ policy, identity, \\ cohesion, heritage.
}


El presente texto tiene como objetivo hacer una revisión histórica de las Introducción estrategias y mecanismos implementados en las políticas culturales ${ }^{1}$ en México; entendiendo como políticas culturales a toda línea de acción gubernamental encaminadas a la conservación del patrimonio cultural y al fomento de la producción y conocimientos de las artes en el país.

Nuestro interés en presentar una muy breve reseña del desarrollo de las políticas culturales en México radica en el deseo de presentar a investigadores, estudiantes y hacedores de política un necesario punto de partida para el análisis y desarrollo de adecuadas políticas públicas relacionadas con el tema. Consideramos que dado el valor y la importancia concedidos a los bienes culturales como promotores de identidad nacional y como impulsores de la cohesión social y el desarrollo ciudadano, es imprescindible fomentar los trabajos que fortalezcan el impacto y la capacidad de implementación de las políticas culturales.

Además de esta introducción, el documento está divido cuatro partes: la primera estudia el desarrollo de las políticas culturales en los periodos históricos del México posindependiente y en el porfiriato, mientras que la segunda y la tercera lo hacen en la época contemporánea. A lo largo del documento, además de examinar las políticas culturales internas, también se revisa la participación de México en tratados y convenios internacionales en la materia. Por último, el presente estudio plantea ciertas reflexiones y observaciones con respecto al desarrollo de las políticas culturales en México. Por cuestiones de espacio, el texto no profundiza en la descripción de los mecanismos que implementan las políticas culturales. 
México alcanzó su independencia el 27 de septiembre de 1821. Ese día todo fue fiesta y celebración, pocos se detuvieron a pensar de qué manera se resolverían los problemas nacionales. Los constantes cambios de gobierno, las intervenciones francesas de 1838 y 1861 y la invasión norteamericana de 1847 provocaron que el alto clero hiciera préstamos forzosos al gobierno manteniendo su influencia en prácticamente todos los sectores de política pública del país incluyendo las incipientes políticas culturales.

Desde los primeros años del México independiente -y hasta finales del siglo XX- las políticas culturales formaban parte de la política educativa. Para este momento "quizá menos del $5 \%$ de la población sabía leer" (Costeloe, 2000, p. 29), estos hombres de bien como los llamó el historiador inglés Michael P. Costeloe, eran los únicos con acceso a contenidos culturales, formaban parte de los gobiernos y consumían libros del extranjero, pero la mayor parte de su tiempo libre lo invertían en diversiones como los naipes y las peleas de gallos.

A pesar de que los hombres de bien no predicaban con el ejemplo, tanto federalistas como centralistas estaban de acuerdo en que la educación -incluyendo las actividades culturales-era lo que necesitaba el país para salir adelante. El hecho de que se utilicen palabras como educación, saber, instrucción o ciencia, no significa que haya ausencia de idea de cultura en los hombres del siglo XIX, sino que "el conjunto de nociones que solemos englobar actualmente en el vocablo cultura, no podía entonces abarcarse bajo un solo término" (Girón, 1982, p. 56). A la educación pública no solamente

\section{Orígenes de las políticas culturales en México: Siglo XIX y porfiriato}


se le asignó la función de alfabetización que requería con urgencia el país, también se le asignaron atributos que contribuyeran a la unidad nacional y con ello la construcción de una identidad cultural. Estos atributos fueron: "promover el uso de un idioma común, definir los valores sociales que le dieran vida y sentido a la patria y crear entre los mexicanos una conciencia de nacionalismo arraigado, capaz de enfrentar agresiones o amenazas externas" (Tovar, 1994, p. 28).

Con la promulgación de la Constitución Federal de los Estados Unidos Mexicanos, el Art. 50 mencionaba las facultades exclusivas del Congreso General. La primera:

promover la ilustración (...) erigiendo uno o más establecimientos en que se enseñen las ciencias naturales y exactas, políticas y morales, nobles artes y lenguas; sin perjudicar la libertad que tienen las legislaturas para el arreglo de la educación pública en sus respectivos Estados (Constitución Federal de los Estados Unidos Mexicanos, 1824).

No solo se pretendía alfabetizar, sino también educar a la población en ciencias, política y arte, es decir, contribuir a la creación de valores morales encaminados a fortalecer un determinado proyecto de nación con la pretensión de lograr una cohesión social. En este proceso de creación de identidad nacional, durante la presidencia de Guadalupe Victoria se creó el Museo Nacional Mexicano (1825) con el objetivo de concentrar piezas antiguas que ayudaran en la formación de una conciencia nacional. Ejemplos de estas piezas fueron la Piedra del Sol y el estandarte de Miguel Hidalgo (Sánchez, 2013, p. 21). 
Durante la primera mitad del siglo XIX se crearon las primeras instituciones culturales. En 1833, en el marco de la creación de la Dirección General de Instrucción Pública para el Distrito Federal y Territorios (Zamora-Patiño, 2002), se fundó la Biblioteca Nacional Pública a partir de los acervos de la desaparecida Universidad Pontificia y el Colegio de Santos (Sánchez, 2013, p. 22). Igualmente, en 1835, se fundó la Academia Mexicana de la Lengua, cuyo principal objetivo era la creación de un diccionario de términos hispano-mexicanos; la Academia cerró en varias ocasiones hasta que fue restablecida en 1854.

La Academia Nacional de la Historia fue organizada en 1836 con la misión de depurar todas las inexactitudes y leyendas que consideraban tenía la historia de México. Al igual que la Academia Mexicana de la Lengua, pasó por varias dificultades y fue reinaugurada en 1854. Se puede afirmar que la institución más exitosa de este periodo fue la Academia de Nobles Artes de San Carlos -fundada a finales del virreinato en 1781; cerrada por falta de recursos en 1834 y reabierta en 1843-al disponerse que las ganancias de la lotería nacional estuvieran destinadas para su financiamiento, lo que le permitió ir aumentando paulatinamente su patrimonio (Sánchez, 2013, p. 23).

Al resultar victoriosos de la guerra de Reforma y el imperio de Maximiliano de Habsburgo, los liberales se dieron a la tarea de consolidar su proyecto cultural estableciendo "el patriotismo como la primera de las virtudes morales" (Girón, 1982, p. 57). Para lograrlo dieron un lugar preponderante a la impartición de la historia de México, pues a partir de este momento "la nación mexicana debía construir su galería de héroes y la leyenda en sus momentos heroicos" (Girón, 1982, p. 78). En esta tarea trabajaron figuras como Guillermo Prieto, Ignacio Ramírez e Ignacio Manuel Altamirano. En las obras escritas de Ramírez y Altamirano, 
maestro y alumno hacen un fiel retrato del mestizo, mientras que adoptan una visión paternalista con el indígena (Girón, 1982, p. 80).

En este periodo también hubo interés en que las artes se constituyeran en el cimiento de la cultura nacional. Ramírez y Altamirano exigieron que la Academia de San Carlos superara sus orígenes neoclásicos y se constituyera en una escuela de pintura mexicana. Es así que "presionado por estas demandas, Ramón Alcaraz, el director de la Academia, lanzó en noviembre de 1869 una convocatoria para un concurso de pinturas históricas de tema mexicano" (Florescano, 2009, p. 459). Ejemplos de las obras participantes tenemos las pinturas El descubrimiento del pulque de José Obregón y El senado de Tlaxcala de Rodrigo Gutiérrez (Florescano, 2009, p. 459). Uno de los egresados más sobresalientes de la Academia de San Carlos en esta época fue José María Velasco, pintor especializado en paisajes, quien tendría su época de mayor renombre después los gobiernos de Juárez y Lerdo de Tejada.

Pero no sería hasta el gobierno de Porfirio Díaz cuando se cumplirían muchas de las metas de los liberales en materia cultural. Este primer periodo de estabilidad política y económica permitió el florecimiento de las actividades culturales y artísticas. En el Porfiriato se dio el primer esfuerzo por contar un relato histórico que unificara las visiones liberal y conservadora de la historia nacional, abonando en la idea de nación. Esta obra fue México a través de los siglos, coordinada por el general liberal e historiador Vicente Riva Palacio. Igualmente, en los últimos años de la época porfirista se establecieron dos instituciones que serían importantes en la cultura de México. La primera fue la Secretaría de Instrucción Pública y Bellas Artes el 16 de mayo de 1905, la segunda fue la Universidad Nacional de México el 18 de junio de 1910 (Zamora, 2002). 
Respecto al Patrimonio Cultural, durante el gobierno de Díaz se le dio prioridad a la preservación de las zonas arqueológicas después de tener la experiencia de las exploraciones del arqueólogo francés Désiré Charnay, quien en 1880 celebró un contrato en el que se le permitía conservar la propiedad de las dos terceras partes de las piezas que descubriera, mientras que la tercera parte restante iría al Museo Nacional de la Ciudad de México (Sánchez, 2013, p. 28). Esto suscitó un debate entre quienes estaban a favor y en contra de que los bienes salieran del país, lo que trajo como consecuencia que se estableciera en 1885 la Inspección General de Monumentos Arqueológicos (Sánchez, 2013, p. 24) y se regularan sus actividades a partir de la expedición de la Ley de Exploraciones Arqueológicas de 1896 y la Ley relativa a los monumentos arqueológicos en 1897 (Cottom, 2001, p. 87).

Para poder dedicarse a las actividades culturales, había que trabajar en el gobierno, por lo que una de las formas de acceder a estos cargos era siendo licenciado en derecho, aunque no se ejerciera. Francisco Bulnes fue uno de estos casos, por eso calcula que antes de la caída del régimen porfirista un $70 \%$ de los intelectuales vivía del presupuesto (Mosiváis, 2010, p. 47). Otro ejemplo fue Federico Gamboa, quien trabajó como diplomático para poder dedicarse a su carrera literaria (Krauze, 1983). Al estallar la Revolución Mexicana, hasta cierto punto era lógico que formaran parte de los opositores, porque en última instancia significaba perder su forma de vida.

El periodo contemporáneo de México tiene como suceso fundacional la Revolución de 1910. El movimiento revolucionario derrocó rápidamente al régimen que le precedió; luego fue sucedido por una serie de enfrentamientos entre las facciones que lo conformaban. La victoria del

\section{La reconstrucción nacional: El factor cultural}


bando constitucionalista puso fin al conflicto armado a gran escala. Para los constitucionalistas su nuevo centro de atención sería la reconstrucción de un país agotado y desquebrajado por los años de constantes enfrentamientos. La constitución de 1917 se convertiría en la base del nuevo régimen conformando de a poco un aparato estatal lo suficientemente sólido que se mantuvo estable por las décadas siguientes apelando siempre al sentimiento nacionalista-revolucionario como articulador de la unidad nacional.

La Revolución se convirtió en el nuevo paradigma nacional (Aguilar, 1983, pp. 107-117). En este proceso de reconstrucción y de redefinición de identidad nacional, el factor cultural fue de vital importancia. El ethos mexicano se fundió con el ideario revolucionario en una alianza indisoluble que marcó el porvenir del siglo XX: había que romper con lo previo, marcar un punto de inflexión. Era un momento de modificaciones estructurales por lo que era urgente desmarcarse de todo aquello que tuviera reminiscencias a viejo régimen.

El México anterior, el de Porfirio Díaz, encontró en el culto a la modernidad, el orden y el progreso su leitmotiv; para conseguirlo apelaron a los modelos de las capitales europeas. Aunque con sus respectivas diferencias, en un inicio la elite podía convivir en el ámbito tradicional con el pueblo, sin embargo, a partir del segundo periodo del General Díaz (1884) se empezó a gestar una ruptura entre la elite y el pueblo en sentido cultural, la cual se estimaba para el régimen como necesaria buscando el correcto avance del país. Todo aquello que se relacionara con la cultura tradicional era visto con desdén por la sofisticada y educada elite porfirista. Por lo tanto, su reacción fue abandonar paulatinamente sus prácticas, 
considerando además al folclor e idiosincrasia popular como elementos atrasados y decadentes que obstaculizaban el progreso de la nación mexicana (Beezley, 2010, pp. 28-29).

En contraste, la facción victoriosa del movimiento revolucionario y el régimen que instituyó buscó desde el inicio una vinculación estrecha con los sectores populares con el fin de encontrar la legitimación necesaria para su consolidación. Ahora, en el proceso de reconfiguración, debían figurar en un lugar importante al menos en lo formal. Por tal motivo, el rescate de 1o "popular" se convirtió en una basa del movimiento triunfante. 
Tabla 1

Convenios multilaterales firmados por México en materia patrimonio cultural

\section{Convenio}

Convenio sobre la protección de instituciones artísticas y científicas y monumentos históricos (Pacto Roerich).

Tratado sobre la protección de muebles de valor histórico.

Convención para la protección de los bienes culturales en caso de conflicto armado.

Convención sobre la protección del Patrimonio Mundial cultural y natural.

Convención sobre la protección del Patrimonio Cultural Subacuático

Segundo protocolo de la

Convención de La Haya de 1954 sobre la protección de los bienes culturales en caso de conflicto armado

Convención para la salvaguardia del Patrimonio Cultural Inmaterial

\section{Firma México Objetivo}

$15 / 04 / 1935$

Preservar los monumentos inmuebles de propiedad nacional y particular que forman parte del tesoro cultural de los pueblos en tiempos de guerra o paz.

$28 / 10 / 1938$

Protección y conservación de los monumentos muebles históricos.

Protección de los bienes culturales en caso de conflicto armado.

Protección colectiva del Patrimonio Cultural y natural de valor excepcional. Garantizar la protección, la conservación y la revalorizar del Patrimonio Cultural y natural.

$02 / 11 / 2001$

Garantizar y fortalecer la protección del Patrimonio Cultural subacuático.

Salvaguarda de los bienes culturales contra los efectos de un conflicto armado

La cooperación internacional para la salvaguardia del Patrimonio Cultural inmaterial; el respeto del Patrimonio Cultural inmaterial; la sensibilización a la importancia del Patrimonio Cultural inmaterial y de su reconocimiento recíproco.

Fuente: Elaboración propia, a partir de Segob (2008). "Protección del Patrimonio Natural y Cultural" en Tratados Vigentes Celebrados por México (1936-2012). Recuperado de: http://www.ordenjuridico.gob.mx/Publicaciones/CDs2012/CDTratados/cd_tratados.php 


\section{Tabla 2}

\section{Convenios multilaterales firmados por México en materia de cooperación cultural}

\section{Convenio}

Convención sobre Canje de

Publicaciones Oficiales Científicas

Literarias e Industriales

Convención sobre facilidades a

exposiciones artísticas.

Convención para el Fomento de las relaciones culturales interamericanas.

Convención sobre facilidades de las películas educativas o de propaganda.

Convención Relativa a las Exposiciones Internacionales.

Acuerdo latinoamericano de coproducción cinematográfica.

Acuerdo para la creación del mercado común cinematográfico.

$11 / 11 / 1989$

Convenio de integración cinematográfica iberoamericana.

Convención sobre la protección y promoción de la diversidad de las expresiones culturales.

\section{Firma México}

$27 / 01 / 1902$

$23 / 12 / 1936$

$23 / 12 / 1936$

$23 / 12 / 1936$

7/12/1982 (adhesión)

Contribuir al efectivo desarrollo de la comunidad cinematográfica de la región y de manera especial en los países con infraestructura insuficiente. 
El nuevo régimen marcaba distancia con el anterior. La nueva elite forjada en los campos batalla miraba con cierto recelo a la elite cultural porfirista debido a que buen número de intelectuales se habían mantenido fieles a Porfirio Díaz, mientras que atacaban o ignoraban a Madero y se mostraban recelosos con otros miembros del movimiento como Emiliano Zapata (Monsiváis, 2010: 28). Esto explica parte del distanciamiento que los líderes políticos revolucionarios mostraban con intelectuales y exponentes de la alta cultura. Aunado a lo anterior, el proyecto de reconstrucción que se ponía en marcha buscaba involucrar a los sectores populares en él: la intelectualidad tendría que ponerse al servicio de esta tarea (Aguilar, 1983, pp. 118-128).

Para 1921, año de la reconstrucción (Krauze, 1983, p. 127), se pusieron en marcha los grandes proyectos nacionales. En materia educativa y cultural, la Secretaría de Educación Pública (SEP) fue creada el 5 de septiembre de 1921 con la intención fundamental de "ejercer una acción vivificante sobre un inmenso territorio abrumado por la ignorancia, la postración y la miseria" (Aguilar, 1983, p. 96). Sin embargo, el objetivo de José Vasconcelos tuvo que hacer frente a innumerables contratiempos desde un inicio, uno de los primeros fue el choque entre su visión educativa y la del régimen; quien veía en la reconstrucción económica y en el desarrollo industrial y agrícola las prioridades urgentes del país (Aguilar, 1983, p. 96). 
Más allá de las vicisitudes el proyecto vasconcelista tuvo grandes méritos y enorme trascendencia. A Vasconcelos se le debe "la incorporación de la cultura en el continente educativo" (Florescano, 2009, p. 485), a partir de ese momento y hasta finales del siglo XX, con la creación del Consejo Nacional para la Cultura y las Artes (Conaculta) en 1989, las políticas culturales estuvieron supeditadas a las políticas educativas. Vasconcelos entendía que la educación y la cultura debían estar rigurosamente unidas. Por tal motivo, se rodeó de un gran número de artistas para su nuevo proyecto: pintores, escultores, músicos, escritores, etc., fueron parte de esta empresa, los cuales se aglutinaron en las tres áreas que conformaban la Secretaría, "Educación, Bellas Artes y Bibliotecas" (Florescano, 2009, p. 485-487).

El realce de lo popular se vio intensificado en la SEP con proyectos puntuales tales como la publicación del libro de Gerardo Murillo Las Artes Populares en México. Con apoyo directo de la Secretaría, el libro constituyó el primer esfuerzo en rescatar estas tradiciones antes poco valoradas. Durante la década de los veinte se desarrolla un auge en el ámbito nacional de las tradiciones populares; canciones, bailes y atuendos se vuelven manifestaciones de lo típicamente mexicano. Las canciones vernáculas y el corrido mezclados con la música clásica se hacen fundamentales en las celebraciones patrias y eventos escolares. Así "mediante libros, revistas, exposiciones, festivales y discursos promovidos desde el aparato educativo, la SEP convierte las artes populares en Patrimonio Cultural protegido por el estado" (Florescano, 2009, pp. 489-492). 
Probablemente el momento más icónico de esta transformación de las políticas culturales estatales ocurrió en la fiesta de conmemoración de la Independencia en 1921, donde se "impusieron los aires folclóricos y populares" (Florescano, 2009, pp. 489-492). El presidente Obregón participó en la inauguración de la exposición de artesanías populares y ofreció premios económicos a las obras de teatro que se presentaran con temática mexicana. Esto contrastó notablemente con la celebración del centenario del grito de Independencia en 1910, encabezada por Porfirio Díaz y en donde el lujo y el glamour marcaron la tónica de la misma (Florescano, 2009, pp. 489-492).

Al igual que estimular la cultura popular, la SEP buscaba alentar y difundir el desarrollo artístico en el territorio nacional. La Dirección de Dibujo y Trabajos Manuales ideo la realización de un manual que incluyera "los métodos básicos del dibujo" (Florescano, 2009, pp. 492493), el cual se destinaría a la "enseñanza en las escuelas primarias". El resultado fue El Tratado de dibujo de Adolfo Best Maugard, el cual recolectaba los principales tipos de diseño desde la época prehispánica hasta la fecha buscando establecer un "alfabeto del arte mexicano" (Florescano, 2009, p. 493). Este proyecto no estuvo exento de críticas que aludían a que el Estado no debía entrometerse en cuestiones estéticas ni técnicas, pues se intentaba acotar la creatividad a "moldes predeterminados" (Florescano, 2009, p. 493). 
Por otra parte, la Dirección de Cultura Estética se encargó de difundir para un público amplio manifestaciones como la música y el teatro. En música, se contó con el apoyo de Manuel M. Ponce, quien ya había pedido se instaurara la obligatoriedad de la enseñanza musical en las escuelas públicas (Florescano, 2009, pp. 492-494). El Departamento de Bibliotecas de la Secretaría también se mantuvo bastante activo. Vasconcelos fue un fuerte promotor de la lectura: en su periodo se alentó la publicación de libros clásicos, revistas para maestros, libros educativos y didácticos, manuales escolares, así como la fundación de buen número de bibliotecas a lo largo del país. Entre otras publicaciones se destacan: La Historia Patria de Justo Sierra, Lecturas clásicas para niños, Lecturas para mujeres y un gran número de obras clásicas de autores como Platón, Dante, Goethe, Cervantes y Tolstoi. (Florescano, 2009, pp. 509-510).

En cuanto a las artes plásticas, los muralistas ocupan un lugar especial. Ya anunciaba Álvaro Obregón en su informe de 1923, que "para estimular a los pintores nacionales [se les había] encomendado la decoración de edificios públicos dependientes a la Secretaría [de Educación Pública]" (Aguilar, 1983, p. 127). Esto fue parte de un gran programa de pintura mural que involucró a los grandes exponentes de esta técnica. José Clemente Orozco, David Alfaro Siqueiros y Diego Rivera plasmaron sus obras en los edificios icónicos de las nuevas instituciones gubernamentales: la Escuela Nacional Preparatoria, el nuevo edificio de la Secretaría de Educación, la Escuela Nacional de Agricultura de Chapingo, Palacio Nacional, etc. Todos ellos plasmaron en sus obras la nueva realidad 
mexicana y su historia, con el pueblo como actor fundamental (Florescano, 2009, pp. 495-508).

Durante el siglo XX las políticas culturales comenzaron a adquirir mayor valor, particularmente en el periodo entre Guerras Mundiales y después de la Segunda Guerra Mundial en el marco de Guerra Fría. Las políticas culturales se inscriben en procesos amplios y vinculadas a "esquemas [de] gobernabilidad interna, diplomacia y seguridad de las naciones [además] refleja el equilibrio geopolítico del momento" (González, 2010, p. 14). Cada país utiliza las políticas culturales con fines claros y específicos. No es de extrañar que en los años treinta se diera una proliferación en la firma de acuerdos internacionales relacionados con la protección y salvaguarda de las artes y el Patrimonio Cultural. Por lo que respecta a México, la primera vez que el país firmó un tratado de este tipo fue en 1902 con la firma de la Convención sobre Canje de Publicaciones Oficiales Científicas Literarias e Industriales, pero no fue sino hasta 1935 que suscribe otro convenio en la materia, el Pacto Roerich, además de suscribir otros tres convenios en vinculados con la cooperación cultural en 1936 y uno más referente Patrimonio Cultural en 1938 (ver tablas uno y dos).

Así, el México posrevolucionario el Estado empleó políticas culturales que fueron vistas como "un medio de cohesión, legitimación y proyección del régimen” (González, 2010, pp. 14-15), todas ellas vinculadas al proyecto educativo vasconcelista. Si bien la línea entre cultura y educación se rompe constantemente en el periodo inicial de la SEP, es de destacar la separación del

\section{Las políticas culturales en el México contemporáneo}


Departamento de Bellas Artes en 1921 como un paso inicial en el proceso de desarrollo de las políticas culturales nacionales en el periodo (Tovar, 1994, pp. 36-37). Varios años después, se sumarían a este proceso la creación del Instituto Nacional de Antropología e Historia (INAH) y el Instituto Nacional de Bellas Artes (INBA) en 1939 y 1946 respectivamente; ambos aún dependientes de la SEP, pero con cierta autonomía y personalidad jurídica propia. Este proceso conlleva, además, una reestructuración profunda en la SEP a lo largo del periodo.

En pleno auge del nacionalismo revolucionario mexicano se anuncia la creación del INAH en el Diario Oficial de la Federación el 3 de febrero de 1939. Dentro de las funciones que tendría el nuevo instituto destacan: la exploración, conservación, vigilancia y restauración de zonas arqueológicas nacionales, monumentos históricos y artísticos, y la realización y publicación de investigaciones científicas y artísticas que interesan a la historia, antropología, etnología y arqueología nacionales con énfasis en la población indígena del país. El INAH formaría su patrimonio con la adhesión de edificios como el Museo Nacional, el ex-convento de La Merced y la parte del Castillo de Chapultepec que se destinaría al Museo de Historia. Se integrarían como sus dependencias: el Museo Nacional de Arqueología, Historia y Etnografía, la Dirección de Monumentos Prehispánicos, y la Dirección de Monumentos Coloniales. Y además de las funciones antes señaladas, tendría adicionalmente las funciones que hasta ese momento desempeñaba el Departamento de Monumentos Históricos, Artísticos y 
Arqueológicos de la República (Diario Oficial de la Federación, 3 de febrero de 1939, pp. 11-12).

Por su parte, el Instituto Nacional de Bellas Artes y Literatura fue creado el 31 de diciembre de 1946. Las funciones que se le atribuyeron al nuevo instituto fueron las siguientes:

I.- El cultivo, fomento, estimulo, creación o investigación de las bellas artes en las ramas de la música, las artes plásticas, las artes dramáticas y la danza, las bellas letras en todos sus géneros y la arquitectura.

II.- La organización y el desarrollo de la educación profesional en todas las ramas de las bellas artes; de la educación artística y literaria comprendida en la educación general que se imparte en los establecimientos de enseñanza preescolar, primaria, de segunda enseñanza y normal (...)

III.- El fomento, la organización y la difusión de las bellas artes, inclusive las bellas letras, por todos los medios posibles y orientada esta última hacia el público en general y en especial hacia las clases populares y la población escolar.

IV.- El estudio y fomento de la televisión aplicada a la realización, en lo conducente, de las finalidades del Instituto.

V.- Las demás que en forma indirecta o derivada correspondan en los términos de esta Ley y de las que resulten aplicables (DOF, 31 de diciembre de 1946, p. 9). 
El patrimonio del nuevo Instituto se conformaría principalmente con la adhesión del nuevo edificio del Conservatorio Nacional; la totalidad de los terrenos que constituían el Club Hípico Alemán; el edificio que ocupaba la Escuela de Danza; el antiguo edificio del Conservatorio Nacional; el edificio de la Escuela Nacional de Artes Plásticas; el Palacio de Bellas Artes; el edificio del Teatro Hidalgo; los terrenos que ocupaba el ex-templo de San Diego; las pinturas y esculturas que integraban la colección de la antigua Academia de San Carlos, y las pinturas y objetos que constituían el Museo de Arte Popular. Posteriormente se anexarían el Conservatorio Nacional de Música; la Escuela de Danza; la Escuela de Pintura y Escultura del Palacio de Bellas Artes; el Departamento de Música; el Departamento de Artes Plásticas; el Departamento de Teatro y Danza, y aquellos que con el tiempo se crearan (DOF, 31 de diciembre de 1946, pp. 9-11).

Dos años después el Instituto ampliaría su patrimonio con la apertura del Museo Nacional de Artes Plásticas. Su creación se anunciaba el 22 de mayo de 1948 en el Diario Oficial de la Federación. Con la creación del Museo se obligaba al Estado a conservar objetos artísticos del pasado, la recolección de obras actuales y futuras. Asimismo, planteaba la necesidad urgente de reunir obras artísticas diversas correspondientes a diversos periodos históricos y la de exhibir las colecciones nacionales de pintura. El nuevo museo tenía la urgente misión de reunir una colección importante de obras nacionales y extranjeras, así como de construir los canales adecuados para la difusión de las artes plásticas. El Museo sería dependiente del 
INBA (DOF, 22 de mayo de 1948), el cual continuó creciendo en las décadas siguientes, ampliando su patrimonio y logrando de a poco consolidarse. $^{2}$

El fin de los años cincuenta presenta cambios sustanciales en las políticas culturales, tanto a nivel internacional, como nacional. En 1959, impulsado por André Malraux, se crea el Ministerio de Cultura en Francia, primer organismo a nivel mundial establecido para el tema cultural (Ejea, 2008, p. 5). En el ámbito nacional, el periodo marca un rompimiento con la política estatal de impulso a lo popular y el nacionalismo que había imperado desde los años de la creación de la SEP. En esta etapa se dio apertura a nuevos enfoques artísticos y a artistas con una perspectiva más cosmopolita. Sin embargo, más allá del cambio temático, las políticas culturales seguían manteniendo un "carácter coyuntural y discrecional” (Ejea, 2008, pp. 4-5). No sería hasta la creación del Conaculta que los intentos por hacer de las políticas culturales una acción gubernamental permanente serían una realidad.

El primer paso en este sentido fue la creación de la Subsecretaría de Cultura, en 1960. Aunque aún dependía de la SEP, la instauración de la Subsecretaría representaba la intención por reconocer que el tema cultural requería de un manejo administrativo particular. La Subsecretaría es dirigida inicialmente por Amalia Caballero de Castillo Ledón y quedaron adscritas a ella el Instituto Nacional de Antropología e Historia, el Instituto Nacional de Bellas Artes, el Instituto Nacional de la Juventud Mexicana, el Departamento de Bibliotecas y la Dirección General de Educación Audiovisual (Tovar, 1994, pp. 46-47).

Pero la Subsecretaría no lograría consolidarse y con cada cambio de estructura sexenal sufría transformaciones de nombre y alcance. Durante 
parte de los años sesenta fue la Subsecretaría de Asuntos Culturales; en 1970, con Luis Echeverría, fue la Subsecretaría de Cultura Popular y Educación Extraescolar; para 1981, con José López Portillo se crea la Subsecretaría de Cultura y Recreación; y para 1982, con Miguel de la Madrid, vuelve a ser la Subsecretaría de Cultura (Ejea, 2009, pp. 19-20).

En estos mismos años (1970 y 1982) México participó en dos grandes reuniones intergubernamentales organizadas por la UNESCO con el fin de abordar el tema de las políticas culturales en el marco internacional. La primera de estas fue la Conferencia Intergubernamental sobre los Aspectos Institucionales, Administrativos y Financieros de las Políticas Gubernamentales desarrollada en Venecia entre el 24 de agosto y el 2 de septiembre de 1970. La finalidad de la Conferencia consistía en examinar los siguientes temas: "la función de los poderes públicos en la determinación y la realización de los objetivos del desarrollo cultural, el fomento y la organización de la acción cultural por los poderes públicos, la investigación sobre las políticas culturales, la cooperación cultural internacional y el papel de la UNESCO en la esfera de las políticas culturales" (UNESCO, 1970, p. 3).

La conferencia detalló en su informe un total de 24 resoluciones y recomendaciones que fluctuaban entre las líneas temáticas antes mencionadas. Es destacable la resolución número 17, la cual menciona que las políticas culturales deben fundarse en datos objetivos y adecuados; después hace la observación de que los datos estadísticos internacionales “en la esfera de la cultura" eran todavía inadecuados. Por tal motivo, invitaba a las organizaciones internacionales a seguir estudiando métodos estadísticos que permitieran establecer estadísticas culturales utilizables para la formulación de políticas culturales fundamentalmente en dos aspectos: el gasto cultural de los poderes públicos y otros organismos y 
particulares involucrados, y en las pautas de comportamiento cultural de los diversos grupos de la población (UNESCO, 1970, p. 24). Esto refleja la complejidad de la implementación de políticas culturales en este periodo.

Doce años más tarde, en la Ciudad de México, la UNESCO llevó a cabo la Conferencia Mundial sobre las Políticas Culturales el 6 de agosto de 1982. En el evento se promulgó la Declaración de México sobre las Políticas Culturales, la cual establece los principios sobre los que debían regirse las políticas culturales: identidad

cultural; dimensión cultural del desarrollo, cultura y democracia; Patrimonio Cultural; creación artística e intelectual y educación artística; relaciones entre cultura, educación, ciencia y comunicación; planificación, administración y financiación de las actividades culturales, y cooperación cultural internacional (UNESCO, 1982, pp. 7-11).

A nivel nacional, en la década de los setenta se consiguió la formalización de una serie de iniciativas culturales que consolidaban las iniciativas de años anteriores, logrando una mayor solidez presupuestal y orden jurídico. El año 1977 fue particularmente importante en este proceso; en este se formalizó la creación de la Compañía Nacional de Teatro (CNT), la Compañía Nacional de Danza (CND), la Compañía Nacional de Ópera (CNO) y el Festival Internacional Cervantino (FIC).

La creación de la CNT se da mediante el Acuerdo publicado en el Diario Oficial de la Federación en julio de 1977. En él se anunciaba que la creación de la Compañía obedecía al propósito del Gobierno Federal por crear instituciones permanentes que contribuyeran al fomento y difusión de las Bellas Artes; la necesidad del INBA por promover el fomento, estímulo, cultivo, creación e investigación de las Bellas Artes; así como la urgencia de un grupo técnico profesional, altamente especializado y 
estable, que constituyera la culminación de las actividades, que en el campo teatral, había hasta el momento realizado el Instituto (DOF, 20 de julio de 1977, pp. 7-8).

Por su parte, el 2 de septiembre se anunciaba la creación oficial de la CND y la CNO. En ambos casos se perseguían objetivos similares a los que guiaban la creación de la CNT, es decir, procurar la promoción y difusión de las Bellas Artes, profesionalizar la educación artística, asegurar presentaciones de alta calidad en cada una de las ramas, acercar estas presentaciones a los sectores populares, etc. (DOF, 2 de septiembre de 1977, pp. 17-18). En los tres casos, las compañías quedan supeditadas al INBA.

E1 Festival Internacional Cervantino tenía ya cinco años realizándose, cuando el 15 de agosto de 1977 se hizo oficial que su sede sería la ciudad de Guanajuato; el Festival sería realizado cada año en la fecha que su comité organizador estimara pertinente. Del Festival se decía que además de apoyar la educación, servía al esparcimiento popular y permitía la "confrontación amistosa" de distintos países, en una celebración, que ya consideraban tradicional en ese momento. Anualmente, la Secretaría de Programación y Presupuesto, asignaría una partida presupuestal procurando la correcta realización del festival (DOF, 15 de agosto de 1977, p. 3).

La época estuvo marcada por otros intentos de modernización de las políticas culturales. Luis Echeverría intentó la creación de un Consejo Nacional de las Artes, idea que fue bien recibida por algunos intelectuales, pero finalmente no procedió. Por su parte, José López Portillo retomó el proyecto y crea el Fondo Nacional para Actividades Sociales, mientras que Miguel de la Madrid plantea la idea de crear una Secretaría de Cultura, sin embargo, ninguna de estas propuestas tuvo el éxito esperado. Fue hasta el siguiente sexenio de Carlos Salinas que la idea es concretada con la creación del 
Consejo Nacional para la Cultura y las Artes (Conaculta) el 7 de diciembre de 1988, tomando forma definitiva el 29 de marzo de 1989 con la expedición del Acuerdo número 151 en marzo de 1989 (González, 2009; DOF, 29 de marzo: 15). La creación del CONACULTA se consolidaba. Al recién creado consejo se le asignaban las siguientes atribuciones:

I.- Promover y difundir la cultura y las artes;

II.- Ejercer, conforme a las disposiciones legales aplicables, las atribuciones que le corresponden a la Secretaría de Educación Pública en materia de promoción y difusión de la cultura y las artes; III.- Coordinar, conforme a las disposiciones legales aplicables, las acciones de las unidades administrativas e instituciones públicas que desempeñan funciones en las materias señaladas en la fracción anterior, inclusive a través de medios audiovisuales de comunicación;

IV.- Dar congruencia al funcionamiento y asegurar la coordinación de las entidades paraestatales que realicen funciones de promoción y difusión de la cultura y las artes, inclusive a través de medios audiovisuales de comunicación, agrupadas o que se agrupen en el subsector de cultura de la Secretaría de Educación Pública; V.- Organizar la educación artística, bibliotecas públicas y museos, exposiciones artísticas, y otros eventos de interés cultural;

VI.- Establecer criterios culturales en la producción cinematográfica, de radio y televisión y en la industria editorial; VII.- Fomentar las relaciones de orden cultural y artístico con los países extranjeros, en coordinación con la Secretaría de Relaciones Exteriores y decidir, o en su caso opinar sobre el otorgamiento de becas para realizar investigaciones o estudios en estas materias; 
VIII.- Planear, dirigir y coordinar las tareas relacionadas con las lenguas y culturas indígenas; fomentar la investigación en estas áreas y promover las tradiciones y el arte popular;

IX.- Diseñar y promover la política editorial del subsector de cultura y proponer directrices en relación con las publicaciones y programas educativos y culturales para la televisión; $y$ X.- Las demás que determine el Ejecutivo Federal y las que le confiera el Secretario de Educación Pública (DOF, 7 de diciembre de 1988, pp. 11-13).

Al nuevo Consejo se adscribirían el Instituto Nacional de Bellas Artes, el Instituto Nacional de Antropología e Historia, el Fondo de Cultura Económica, el Fondo Nacional para el Fomento de las Artesanías, el Festival Internacional Cervantino, Educal, el Centro Cultural de Tijuana, la Biblioteca de México y Radio Educación (Tovar, 1994, pp. 60-61).

Al mismo tiempo que surge Conaculta, también se crea el Fondo Nacional para la Cultura y las Artes (Fonca) con el que se buscaba "generar un sistema de becas y estímulos que permitiera a los creadores y artistas tener los recursos suficientes para poder realizar de manera estable su trabajo sin presiones económicas” (Ejea, 2008, p. 5). Tanto el Conaculta como el Fonca eran concebidos como instrumentos que permitirían una apertura y una democratización en la entrega de recursos destinados a la estimulación artística.

Una pieza más del nuevo sistema cultural estatal sería el Sistema Nacional de Creadores de Arte (SNCA), cuya creación fue decretada el 3 de septiembre de 1993. Según el Acuerdo que anunciaba la creación del Sistema, el Plan Nacional de Desarrollo 1989-1994 contemplaba en el apartado de las políticas culturales gubernamentales el estímulo a la creatividad artística mediante, "el otorgamiento de becas de alto nivel para 
que, por un tiempo determinado, los artistas e intelectuales se dediquen exclusivamente a la obra de creación" (DOF, 3 de septiembre de 1993, p. 103). Con esto se buscaba estimular a los creadores e incrementar el Patrimonio Cultural del país. El Sistema sería dependiente de la SEP, a través del Conaculta. Los objetivos del SNCA eran los siguientes:

I.- Contribuir al fomento y reconocimiento de la actividad creativa en las artes como parte fundamental de la identidad nacional;

II.- Promover y establecer los mecanismos que permitan otorgar becas de alto nivel, distinciones, reconocimientos y otros estímulos a quienes han dado prestigio a México en el ámbito de la creación de arte, tanto por su desempeño protagónico como por los niveles de excelencia que haya alcanzado su obra artística;

III.- Instituir programas y realizar acciones de fomento y apoyo al artista que le proporcionen mejores condiciones para la creación; y IV.- Revalorar la actividad de quienes han entregado su esfuerzo creativo de arte para el enriquecimiento del legado cultural de nuestro país (DOF, 3 de septiembre de 1993, p. 103).

Pocos meses antes de la creación del SNCA, en abril de 1993, Carlos Salinas anunciaba que, como parte del Acuerdo Nacional para la Modernización Educativa, se contemplaba la creación del Centro Nacional de las Artes (Cenart), el centro aparece como "último estadio de la educación artística". Siendo el "catalizador de un proceso educativo que conjuga excelencia académica y estímulo a la creación” (Tovar, 1994, pp. 309-318). En el Centro se reunirían: el Conservatorio Nacional de Música; la Escuela Nacional de Pintura, Escultura y Grabado "La Esmeralda"; el Sistema Nacional para la Enseñanza Profesional de la Danza; la Escuela de Arte Teatral; y, el Centro de Capacitación Cinematográfica. El centro trabajaría fundamentalmente basado en los principios de 
interdisciplinariedad, estableciendo lazos entre la práctica profesional y la investigación, y en la especificidad de la enseñanza artística, aquí sería fundamental su vinculación con el SNCA, cuya creación se anunciaría en los meses siguientes. El Centro también reuniría a los cuatro centros de investigación existentes al momento: en música el CENIDIM (1974); en danza el CENIDI (1983); en teatro el CITRU (1977); y en artes plásticas el CENIDIAP (1985). El Centro se pensaba como una unión entre el trabajo académico de investigación profunda y el constante estímulo a la creación artística (Tovar, 1994, pp. 309-318).

La llegada de los años noventa y el consiguiente fin de la Guerra Fría llevaron a las políticas culturales a un nuevo escenario. La intensificación de los acuerdos comerciales internacionales involucró a las industrias culturales en un proceso de globalización. En la Ronda de Uruguay (19861994), los países miembros del General Agreement of Trade and Traffics (GATT) deliberaron sobre nuevas regulaciones comerciales; el debate incluía a las industrias nacionales, incluidas las industrias culturales. Del debate surgen dos bandos como resultado de la posición francesa de apelar a la "excepción cultural" que proponía mantener los contenidos audiovisuales, en particular el cine, fuera de los productos y servicios que se buscaban "liberar" (Frau-Meigs, 2014, s. p.). Por un lado, los hiperliberales consideraban los contenidos audiovisuales como industrias de entretenimiento que simplemente debían integrarse a las reglas del mercado. Por su parte, los excepcionistas creían que los contenidos audiovisuales eran un arte, por lo tanto, debían formar parte del patrimonio nacional (Frau-Meigs, 2014, s. p.). La respuesta latinoamericana a este debate se presenta con la firma de tres tratados en 1989 sobre producción, creación y distribución cinematográfica (Tabla 2). 
El proceso de construcción del Tratado de Libre Comercio de América del Norte (TLCAN) -primer tratado de este tipo firmado por México- se mantuvo ajeno al debate que se desarrollaba entre la Unión Europea y los Estados Unidos. Si bien en el decreto de promulgación del TLCAN se incluía a las industrias culturales en el artículo 2106, del capítulo XXI (excepciones), no se profundizaba mucho en su protección (DOF, 20 de diciembre de 1993, p. 44).

Si bien después de los años noventa no hubo mayores cambios en las políticas culturales internas, si existió un nuevo impulso en la protección del Patrimonio Cultural y el fomento a las artes en el ámbito de las relaciones internacionales. Después de trece años de no firmar nuevos pactos internacionales en la materia, en 2001 México suscribe la Convención sobre la protección del Patrimonio Cultural Subacuático y en 2003 se adhiere al Segundo protocolo de la Convención de La Haya de 1954 sobre la protección de los bienes culturales en caso de conflicto armado. Es en este mismo año cuando se firma la Convención para la salvaguardia del Patrimonio Cultural Inmaterial, sin embargo, México no se adhiere al pacto hasta dos años después (ver tablas uno y dos). Cabe destacar que este último tratado tuvo un importante impacto en la política interna del país no solo en materia cultural, sino también en lo que respecta a la política social: esta Convención establece algunos de los principios normativos para el desarrollo de la vertiente Centros Históricos del Programa Hábitat (Ortiz et al., 2013, pp. 165-187). 
Como hemos visto a lo largo de este documento, el proceso evolutivo de las políticas culturales en México comúnmente ha estado marcado por el proyecto político vigente y en la mayoría de los casos, forma parte de proyectos más grandes que las veían como instrumentos propicios para la cohesión social, la legitimación o la promoción del proyecto político en cuestión.

Igualmente, se ha visto en el desarrollo de este documento que las líneas de acción de construcción de las políticas culturales en México han estado claramente influenciadas por los acontecimientos y propuestas llevadas a cabo en el contexto internacional. Esta situación resulta muy notoria en los últimos años en los que los cambios más importantes, en cuanto a política cultural se refiere, se desarrollan en el marco de las relaciones internacionales.

Pero ya sea como consecuencia de procesos internos o de cambios provenientes de la política exterior, las propuestas para la implementación de las políticas culturales están íntimamente relacionadas con la difusión y promoción de las artes como herramienta para la creación de una identidad y cohesión social, así como con la intención de impulsar y mejorar los procesos educativos. Sin embargo, más allá de la planeación e implementación de las políticas culturales en México, hace falta una fase fundamental en el proceso de elaboración de las políticas públicas: la evaluación.

Para desarrollar una política pública es indispensable primeramente establecer cuál es el problema que se va a resolver. En el caso de las políticas culturales, hemos visto que el problema obedece a dos vertientes: la cohesión social y la mejora educativa. No obstante, para ninguno de estos dos problemas han existido iniciativas que contribuyan a conocer la 
efectividad y los resultados -al menos no en lo que refiere al impacto que provocan- que la implementación de las políticas culturales arroja.

No se puede negar que han existido esfuerzos importantes para conocer el alcance de las políticas culturales en México como lo son el Sistema de Información Cultural (SIC) que funciona como una enorme base de datos que integra información actualizada derivada de los datos que se tienen en el ámbito estatal (SIC, 2015, s. p.); la Encuesta Nacional de Consumo Cultural de México (ENCCUM) para únicamente el año 2012 y en la que se observan el gasto en los hogares en materia cultural, y la Encuesta Nacional sobre Uso del Tiempo (ENUT) para 2002, 2009 y 2014, la cual tiene como finalidad saber el tiempo que la población le dedica a diversas actividades (INEGI, 2015, s. p.). Sin embargo, ninguna de estas herramientas evalúa si las políticas culturales en México efectivamente están logrando resolver o siquiera aminorar los problemas, por los cuales, si justifica su implementación, esto es, propiciar la cohesión social y mejorar los niveles de educación de la población en México.

Ciertamente el desarrollo de efectivas políticas culturales puede considerarse un problema no prioritario en la agenda gubernamental, pues existen problemas que requieren mayo urgencia como la insuficiencia en el acceso a la salud, empero, políticas culturales eficientes que persigan el fin real por el que fueron creadas atenúan problemas más graves en materia de política social. Las políticas culturales bien implementadas no solo tienen una capacidad potencial para mejorar los niveles educativos y establecer vínculos nacionales que proveen de estabilidad social, sino que también son capaces de mejorar el desarrollo psicosocial de la población, así como de contribuir al desarrollo económico a partir de un sector que no ha sido explotado del todo, o que al menos no se puede saber bien a bien su alcance al no tener herramientas adecuadas para poder realizar una evaluación certera y adecuada. 
Acuerdo número 151, por el que se delegan facultades en el presidente del

\section{Referencias} Consejo Nacional para la Cultura y las Artes, en: Diario Oficial de la Federación, México D.F., miércoles 29 de marzo de 1989, tomo CDXXVI, número 20. Recuperado de: http://www.dof.gob.mx/index.php?year=1989\&month=03\&day=29

Aguilar, H. (1983). "Nociones presidenciales de cultura nacional. De Álvaro Obregón a Gustavo Díaz Ordaz, 1920-1968”. En: VVAA. En torno a la cultura nacional. D. F., México: Fondo de Cultura Económica, pp. 93-133.

Beezley, W. (2010). Judas en el Jockey Club y otros episodios del México porfiriano, México, El Colegio de San Luis/ Centro de Investigaciones y Estudios Superiores en Antropología Social, p. 206.

Bonfil, C. (2010). “Cine”, en "El estado de las artes", VVAA, Letras Libres, número 137, mayo 2010, pp. 26-27. Recuperado de: http://www.letraslibres.com/sites/default/files/pdfs_articulos/pdf_art _14626_12782.pdf

Costeloe, M. (2000). La república central en México, 1835-1846.

"Hombres de bien" en la época de Santa Anna. D. F., México: Fondo de Cultura Económica.

Cottom, B. (2001). "Patrimonio Cultural nacional: Marco jurídico y conceptual". Derecho y cultura, 4. Recuperado de: http://www.juridicas.unam.mx/publica/rev/indice.htm?r=derycul\&n $=4$

DOF. (1939). Ley orgánica del Instituto Nacional de Antropología e Historia. Recuperado de: http://www.dof.gob.mx/index.php?year=1939\&month=02\&day=03

DOF. (1946). Ley que crea el Instituto Nacional de Bellas Artes y Literatura. Recuperado de: http://www.dof.gob.mx/index.php?year=1946\&month=12\&day=31 
DOF. (1948). Decreto que crea el Museo de Artes Plásticas, dependiente de Instituto Nacional de Bellas Artes. Recuperado de:

http://www.dof.gob.mx/index.php?year=1948\&month=05\&day=22

DOF. (1977). Acuerdo por el que la Secretaría de Educación Pública autorizará el establecimiento de la Compañía Nacional de Danza, como una dependencia del Instituto Nacional de Bellas Artes y Literatura. Recuperado de:

http://www.dof.gob.mx/index.php?year=1977\&month=09\&day=02

DOF. (1977). Acuerdo por el que la Secretaría de Educación Pública autorizará el establecimiento de la Compañía Nacional de Ópera, como una dependencia del Instituto Nacional de Bellas Artes y Literatura. Recuperado de:

http://www.dof.gob.mx/index.php?year=1977\&month=09\&day=02

DOF. (1977). Acuerdo por el que la Secretaría de Educación Pública autorizará el establecimiento de la Compañia Nacional de Teatro, como una dependencia del Instituto Nacional de Bellas Artes y Literatura. Recuperado de: http://www.dof.gob.mx/index.php?year=1977\&month=07\&day=20

DOF. (1977). Decreto por el que se establece que cada año y en la fecha que con oportunidad se dé a conocer, tendrá lugar el Festival Internacional Cervantino, con sede en la ciudad de Guanajuato. Recuperado de: http://www.dof.gob.mx/index.php?year=1977\&month=08\&day=15

DOF. (1988). Decreto de creación del Consejo Nacional para la Cultura y las Artes, como órgano administrativo desconcentrado de la Secretaría de Educación Pública que ejercerá las atribuciones de promoción y difusión de la cultura y las artes. Recuperado de: http://www.dof.gob.mx/index.php?year=1988\&month=12\&day=07

DOF. (1993). Acuerdo que establece el Sistema Nacional de Creadores de Arte. Recuperado de:

http://www.dof.gob.mx/index.php?year=1993\&month=09\&day=03 
DOF. (1993). Decreto de promulgación del Tratado de Libre Comercio de América del Norte, en: Diario Oficial de la Federación. Recuperado de:

http://www.dof.gob.mx/index.php?year=1993\&month=12\&day=20

Ejea, T. (2008). "Las políticas culturales de México en los últimos años”. Casa del tiempo, 1, (5), pp. 2-7. Recuperado de: http://www.difusioncultural.uam.mx/casadeltiempo/05_iv_mar_200 8/casa_del_tiempo_eIV_num05-06_02_07.pdf

Ejea, T. (2009). "La liberalización de las políticas culturales en México: el caso del fomento a la creación artística”. Sociológica, 24, (71), pp. 17-46. Recuperado de: http://www.revistasociologica.com.mx/pdf/7103.pdf

Florescano, E. (2009). “José Vasconcelos y la construcción del nacionalismo del siglo XX”. En Enrique Florescano, Ensayos fundamentales, pp. 485-510. Taurus: El Colegio de México.

Frau-Meigs, D. (2014). "Excepción cultural, políticas nacionales y globalización: factores de democratización y de promoción de lo contemporáneo". Reflexiones marginales, 2, (12). Recuperado de: $\mathrm{http}: / /$ reflexionesmarginales.com/3.0/excepcion-cultural-politicasnacionales-y-globalizacion-factores-de-democratizacion-y-depromocion-de-lo-contemporaneo/

Girón, N. (1982). 'La idea de la 'cultura nacional' en el siglo XIX: Altamirano y Ramírez”. En Pacheco, Girón, et. al., En torno a la cultura nacional, p. 51-83. México, Fondo de Cultura Económica.

González, A. (2010), "Las políticas culturales y sus reyertas”. Letras Libres, 137, pp. 14-17. Recuperado de: http://www.letraslibres.com/sites/default/files/pdfs_articulos/pdf_art _14620_12780.pdf

González, H. (2009). “Conaculta: el tiempo transcurrido”. Fondo de Cultura Económica. Recuperado de:

http://www.fondodeculturaeconomica.com/editorial/prensa/Detalle.a spx? seccion $=$ Detalle\&id_desplegado $=24073$ 
INEGI. (2012). Encuesta Nacional de Consumo Cultural de México (ENCCUM). Recuperado de:

http://www.inegi.org.mx/est/contenidos/proyectos/encuestas/hogares /especiales/enccum/2012/default.aspx

INEGI. (2002, 2009, 2014). Encuesta Nacional sobre Uso del Tiempo (ENUT). Recuperado de:

http://www.inegi.org.mx/est/contenidos/proyectos/encuestas/hogares /especiales/enut/default.aspx

Instituto de Investigaciones Jurídicas UNAM. (1823). Constitución Federal de los Estados Unidos Mexicanos. Recuperado de: http://www.juridicas.unam.mx/infjur/leg/conshist/

Instituto de Investigaciones Jurídicas UNAM. (1836). Leyes Constitucionales. Recuperado de: http://www.juridicas.unam.mx/infjur/leg/conshist/pdf/1836.pdf

Instituto de Investigaciones Jurídicas UNAM. (1857). Constitución Política de la República Mexicana. Recuperado de: http:/www.juridicas.unam.mx/infjur/leg/conshist/

Krauze, E. (1983). "Cuatro estaciones de la cultura mexicana”. En Enrique Krauze, Caras de la historia, pp. 124-168. México, Joaquín Mortiz.

Monsiváis, C. (2010). La cultura mexicana en el siglo XX. México, Colegio de México.

Ortiz, A., Cabrero, I. \& Hernández, J. (2013). "Más que la suma de las partes: análisis del Programa Hábitat Vertiente Centros Históricos”. Perspectivas de Políticas Públicas, 3, (4), pp. 165-187. Buenos Aires: Universidad de Lanús.

Sánchez, J. (2013). “La travesía del Patrimonio Cultural nacional”. En Patrimonio Cultural. Ensayos de cultura y derecho, México, UNAM. Recuperado de: http://biblio.juridicas.unam.mx/libros/7/3233/4.pdf

Segob. (1902). Convención sobre Canje de Publicaciones Oficiales Científicas Literarias e Industriales. Recuperado de: http://www.ordenjuridico.gob.mx/Publicaciones/CDs2012/CDTratad os/pdf/M8.html 
Segob. (1935). Convenio sobre la protección de instituciones artísticas y científicas y monumentos históricos (Pacto Roerich). Recuperado de:

http://www.ordenjuridico.gob.mx/Publicaciones/CDs2012/CDTratad os/pdf/M84.html

Segob. (1936). Convención para el Fomento de las relaciones culturales interamericanas. Recuperado de:

http://www.ordenjuridico.gob.mx/Publicaciones/CDs2012/CDTratad os/pdf/M104.html

Segob. (1936). Convención sobre facilidades a exposiciones artísticas.

Recuperado de:

http://www.ordenjuridico.gob.mx/Publicaciones/CDs2012/CDTratad os/pdf/M100.html

Segob. (1936). Convención sobre facilidades de las películas educativas o de propaganda. Recuperado de:

http://www.ordenjuridico.gob.mx/Publicaciones/CDs2012/CDTratad os/pdf/M103.html

Segob. (1938). Tratado sobre la protección de muebles de valor histórico.

Recuperado de:

http://www.ordenjuridico.gob.mx/Publicaciones/CDs2012/CDTratad os/pdf/M85.html

Segob. (1954). Convención para la protección de los bienes culturales en caso de conflicto armado. Recuperado de:

http://www.ordenjuridico.gob.mx/Publicaciones/CDs2012/CDTratad os/pdf/

Segob. (1982). Convención Relativa a las Exposiciones Internacionales.

Recuperado de:

http://www.ordenjuridico.gob.mx/Publicaciones/CDs2012/CDTratad os/pdf/M60.html

Segob. (1984). Convención sobre la protección del Patrimonio Mundial cultural y natural. Recuperado de:

http://www.ordenjuridico.gob.mx/Publicaciones/CDs2012/CDTratad os/pdf/M308.html 
Segob. (1989). Acuerdo latinoamericano de coproducción cinematográfica. Recuperado de:

http://www.ordenjuridico.gob.mx/Publicaciones/CDs2012/CDTratad os/pdf/M474.html

Segob. (1989). Acuerdo para la creación del mercado común cinematográfico. Recuperado de:

http://www.ordenjuridico.gob.mx/Publicaciones/CDs2012/CDTratad os/pdf/M475.html

Segob. (1989). Convenio de integración cinematográfica iberoamericana.

Recuperado de:

http://www.ordenjuridico.gob.mx/Publicaciones/CDs2012/CDTratad os/pdf/M476.html

Segob. (2001). Convención sobre la protección del Patrimonio Cultural Subacuático y Convención para la salvaguardia del Patrimonio Cultural Inmaterial. Recuperado de:

http://www.ordenjuridico.gob.mx/Publicaciones/CDs2012/CDTratad os/pdf/M622.html

Segob. (2003). Segundo protocolo de la Convención de La Haya de 1954 sobre la protección de los bienes culturales en caso de conflicto armado. Recuperado de:

http://www.ordenjuridico.gob.mx/Publicaciones/CDs2012/CDTratad os/pdf/M568.html

Segob. (2005). Convención sobre la protección y promoción de la diversidad de las expresiones culturales. Recuperado de: http://www.ordenjuridico.gob.mx/Publicaciones/CDs2012/CDTratad os/pdf/M613.html

Segob. (2005). Convención para la salvaguardia del Patrimonio Cultural Inmaterial. Recuperado de:

http://www.ordenjuridico.gob.mx/Publicaciones/CDs2012/CDTratad os/pdf/M602.html

Serrano, J. A. \& Vázquez, J. Z. (2010), “Cultura mexicana, 1821-1850”. En Velásquez García, Nalda, et al., Nueva Historia General de México, pp. 437-441. México: Colegio de México. 
SIC. (2015). Sobre el Sistema de Información Cultural. Recuperado de: http://sic.conaculta.gob.mx/sobre_sic.php

Tovar, R. (1994). Modernización y políticas culturales. D. F., México: Fondo de Cultura Económica.

UNESCO. (1970). Informe final de la Conferencia Intergubernamental sobre los Aspectos Institucionales, Administrativos y Financieros de las Politicas Culturales. Recuperado de: http://unesdoc.unesco.org/images/0009/000928/092837SB.pdf

UNESCO. (1982). Declaración de México sobre las Políticas Culturales. Aprobada por la Conferencia Mundial sobre las Políticas Culturales. Recuperado de: http://unesdoc.unesco.org/images/0005/000546/054668mb.pdf

Zamora, M. P. (2002). "Legislación educativa". En Galván, Lazarín, et al., Diccionario de Historia de la Educación en México. UNAMCIESAS-UAM-UIA. Recuperado de: http://biblioweb.tic.unam.mx/diccionario/htm/articulos/sec_4.htm 
1. El término será utilizado en plural debido a que no existe una única línea de acción gubernamental diseñada para difundir y proteger las artes y el patrimonio cultural, sino que son diversos los mecanismos, estrategias y estructuras gubernamentales construidas con tales fines.

2. Entre las décadas de los cincuenta y sesenta se construyeron: la Unidad Artística y Cultural del Bosque, en 1964; el Museo de Arte Moderno; la Pinacoteca Virreinal; y se restaura el Palacio de Buenavista, donde se instala el Museo de San Carlos en 1965 (Tovar, 1994, pp. 43-44).

\section{Recibido: 18-noviembre-2015 Aceptado: 11-febrero-2016}

Todos los derechos reservados. Universidad de Costa Rica. Esta revista se encuentra licenciada con Creative Commons Reconocimiento-NoComercialSinObraDerivada 3.0 Costa Rica. (CC BY-NC-SA 3.0 CR)

Correo electrónico: humanidades@ucr.ac.cr Sitio web: http://revistas.ucr.ac.cr/index.php/humanidades 